\title{
Simultaneous determination of eight catechins and four theaflavins in green, black and oolong tea using new HPLC-MS-MS method
}

\author{
Wuqun Tao ${ }^{\mathrm{a}, \mathrm{b}}$, Zhiguang Zhou ${ }^{\mathrm{c}, *}$, Bin Zhao ${ }^{\mathrm{a}, \mathrm{b}, * *}$, Tongyu Wei $^{\mathrm{d}}$ \\ a State Key Laboratory of Environmental Chemistry and Ecotoxicology, Research Center of Eco-Environment Sciences, Chinese Academy of Sciences, Beijing, \\ 100085, China \\ b University of Chinese Academy of Sciences, Beijing 100049, China \\ c State Environmental Protection Key Laboratory of Dioxin Pollution Control, National Research Center for Environmental Analysis and Measurement, \\ Beijing, 100029, China \\ d Tianjin Solid Waste and Toxic Chemical Management Center, Tianjin, 300191, China
}

\section{A R T I C L E I N F O}

\section{Article history:}

Received 1 June 2016

Received in revised form 20 August 2016

Accepted 25 August 2016

Available online 26 August 2016

\section{Keywords:}

Catechins

Theaflavins

HPLC-MS-MS

Green tea

Black tea

Oolong tea

\begin{abstract}
A B S T R A C T
A simple, rapid and accurate analytical method was developed for the analysis of eight tea catechins and four theaflavins simultaneously in three types of tea (green, black and oolong tea), using ultra high performance liquid chromatography coupled with triple-quadrupole tandem mass spectrometry (HPLC-MS-MS) in multiple-reaction monitoring (MRM) mode. This method using HPLC-MS-MS in positive mode was performed on a CAPCELL PAK C18 MGIII $(2.0 \mathrm{~mm} \times 100 \mathrm{~mm}, 3 \mu \mathrm{m})$ column (Shiseido) with the mobile phase consisting of $0.1 \%$ aqueous formic acid (A) and methanol (B) in gradient elution at a flow rate of $0.3 \mathrm{~mL} \mathrm{~min}^{-1}$, and the column temperature set at $30^{\circ} \mathrm{C}$. The optimized HPLC-MS-MS methodology is selective and specific, and was validated for eight catechins and four theaflavins widely reported in different teas. Satisfactory linearity was achieved in linear range $\left(0.02-5 \mu \mathrm{g} \mathrm{mL}^{-1}\right.$ for catechins and $0.02-20 \mu \mathrm{g} \mathrm{mL}^{-1}$ for theaflavins) and fine determination coefficient $\left(\mathrm{r}^{2}>0.9935\right)$. The recoveries ranged from $65 \%$ to $115 \%$ with the RSD ranging from $2.4 \%$ to $6.7 \%$. The methodology was used to evaluate the target polyphenols concentration in three types of tea samples.
\end{abstract}

(ㄷ) 2016 Elsevier B.V. All rights reserved.

\section{Introduction}

As one of the most popular beverages in the world, tea consumption has attracted substantial interests in understanding the benefits of polyphenolic flavonoids in tea, which can be used as health supplement. Tea polyphenols are an important group of natural compounds that have gained popularity as ingredients in dietary supplements and functional foods. Tea polyphenols have also been reported to possess a variety of biological properties that have positive impact on human health [1-3], which includes anti-inflammatory, anti-obesity effects and reduced risk of cardiovascular diseases and cancer [4-8]. Green, black and oolong teas are rich sources of polyphenols, the most abundant being catechins and theaflavins. The three major varieties of tea

\footnotetext{
* Corresponding author.

** Corresponding author at: State Key Laboratory of Environmental Chemistry and Ecotoxicology, Research Center of Eco-Environment Sciences, Chinese Academy of Sciences, Beijing, 100085, China.

E-mail addresses: zzguang2004@hotmail.com (Z.Zhou), binzhao@rcees.ac.cn (B. Zhao).
}

are generally categorized by the process used in their production: unfermented (non-oxidized) green tea, fermented (oxidized) black tea and semi-fermented (semi-oxidized) oolong tea $[9,10]$. The main catechins present in green tea are (+)-catechin (C), $(-)$-catechin gallate (CG), (-)-epicatechin (EC), (-)-epicatechin gallate (ECG), (-)-epigallocatechin (EGC), (-)-gallocatechin (GC), (-)-gallocatechin gallate (GCG) and (-)-epigallocatechin gallate (EGCG) (Fig. 1). Theaflavins (TF) are another group of polyphenol pigments, including theaflavin $\left(\mathrm{TF}_{1}\right)$, theaflavin-3-gallate $\left(\mathrm{TF}_{2} \mathrm{~A}\right)$, theaflavin-3'-gallate $\left(\mathrm{TF}_{2} \mathrm{~B}\right)$ and theaflavin-3, 3'-digallate $\left(\mathrm{TF}_{3}\right)$, found in both black and oolong teas (Fig. 1). Their content correlates well with the quality and selling price of teas [11]. Structural formulas of eight tea catechins and four main theaflavins are shown in Fig. 1. For consumers' health it is very important to know the quantity of these beneficial compounds in tea infusions. In addition, considering the contribution of catechin and theaflavin to the quality of tea, a reliable quantitative analysis of these compounds is needed for manufacturers of dietary supplements and the quality control authorities. A variety of analytical methods have been used for the analysis of these phenolic compounds in teas: high-performance liquid chromatography [12-18], 
<smiles>Oc1cc(O)c2c(c1)O[C@@H](c1ccc(O)c(O)c1)[C@@H](O)C2</smiles><smiles>Oc1cc(O)c2c(c1)OC(c1ccc(O)c(O)c1)C(O)C2</smiles><smiles>O=C(OC1Cc2c(O)cc(O)cc2OC1c1cc(O)c(O)c(O)c1)c1ccccc1</smiles>
(-)-Catechin gallate<smiles>O=C1C(O)=CC(C2Oc3cc(O)cc(O)c3C[C@H]2O)C=C2c3c(O)c(O)cc(C4Oc5cc(O)cc(O)c5C[C@H](O)C4O)c3OC12</smiles>

Theaflavin
$(+)$-Catechin<smiles>O=C(O[C@H]1Cc2c(O)cc(O)cc2OC1c1cc(O)c(O)c(O)c1)c1cc(O)c(O)c(O)c1</smiles>

(-)-Gallocatechin gallate

(-)-Gallocatechin

(-)-Epigallocatechin<smiles>CC(O)c1cc([C@H]2Oc3cc(O)cc(O)c3C[C@H]2OC(=O)c2cc(O)c(O)c(O)c2)ccc1O</smiles>

(-)-Epicatechin gallate<smiles>O=C(O[C@H]1Cc2c(O)cccc2O[C@H]1c1cc(O)c(O)c(O)c1)c1cc(O)c(O)c(O)c1</smiles>

(-)-Epigallocatechin gallate

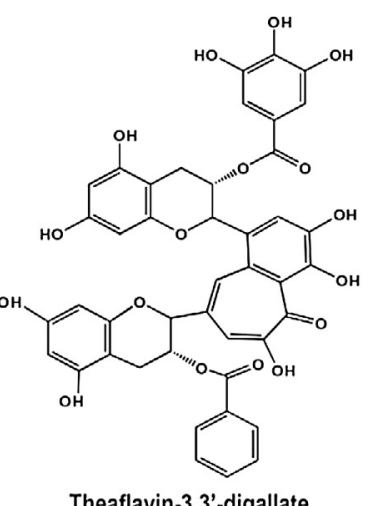

Fig. 1. Structures of eight tea catechins and four major theaflavins.

liquid chromatography-mass spectrometry [19-21] and liquid chromatography tandem mass spectrometry (LC-MS/MS) [22,23]). HPLC is the most widely used technique [12-18]. Numerous investigations on analytical methods for tea polyphenols were reported [24-27], but simultaneous separation and quantification of tea catechins and main theaflavins in one single run is rarely reported [28]. Furthermore, HPLC-MS-MS methods have never been developed for simultaneous analysis of eight catechins and four theaflavins in green, black tea and oolong tea. To develop and validate a rapid, sensitive and selective HPLC-MS-MS method is important for simultaneous determination of eight primary tea catechins and four main theaflavins in tea infusions. This method can be widely used for tea quality estimation and quantitative analysis of tea polyphenols.

The main objectives of this study were to design and validate the improved methods using HPLC-MS-MS to simultaneously measure the concentrations of eight tea catechins and four theaflavins in a single run, and to demonstrate applicability of method to the analysis of real sample (three different types of tea infusion). Analytical parameters such as matrix effects, recoveries, reproducibility, limits of detection (LODs) and limits of quantification (LOQs) of the methods were also evaluated. Finally, three types of tea samples were analyzed to demonstrate the developed method, as well as the distribution character of twelve compounds was investigated.

\section{Methods and procedure}

\subsection{Chemicals and reagents}

(+)-Catechin (C), (-)-catechin gallate (CG), (-)-epicatechin (EC), (-)-epicatechin gallate (ECG), (-)-epigallocatechin (EGC), (-)-epigallocatechin gallate (EGCG), (-)-gallocatechin (GC), (-)gallocatechin gallate (GCG), theaflavin $\left(\mathrm{TF}_{1}\right)$, theaflavin-3-gallate $\left(\mathrm{TF}_{2} \mathrm{~A}\right)$, theaflavin-3'-gallate $\left(\mathrm{TF}_{2} \mathrm{~B}\right)$ and theaflavin-3, 3'-digallate $\left(\mathrm{TF}_{3}\right)$ were purchased from Sigma-Aldrich (Steinheim, Germany). Water was prepared using a Milli-Q water purification system (Millipore, Billerica, MA, USA). Methanol (HPLC grade) was purchased from Thermal fisher; Formic Acid (LC-MS grade) was purchased from Fluka.

\subsection{Sample collection and preparation}

Three types of commercial teas, both of high and low grade for each tea, were randomly selected and purchased at a local market. There were three types of common Chinese tea including Xihu Longjing (Chinese green tea), Dianhong (Chinese black tea) and Anxi Tieguanyin (Chinese oolong tea). For each tea sample, approximately $1.0 \mathrm{~g}$ of dry tea leaves was brewed with $100 \mathrm{~mL}$ of hot water $\left(80^{\circ} \mathrm{C}\right)$ for $3 \mathrm{~min}$ with mild stirring. This procedure was repeated 5 times, where the hot water was added at the beginning of each brewing cycle. The cooled down tea infusion was filtrated through 
Table 1

Optimized HPLC-ESI-MS/MS parameters for analysis of the analytes by MRM.

\begin{tabular}{llll}
\hline Compound & Rt $(\mathrm{min})$ & Transitions & Collision Energy $(\mathrm{eV})$ \\
\hline Gallocatechin & 1.29 & $307>139$ & 10 \\
Epigallocatechin & 2.08 & $307>139$ & 10 \\
Catechin & 2.30 & $291>139$ & 10 \\
Epigallocatechin gallate & 3.62 & $459>139$ & 10 \\
Epicatechin & 4.30 & $291>139$ & 10 \\
Gallocatechin gallate & 5.37 & $459>139$ & 10 \\
Epicatechin gallate & 6.98 & $443>123$ & 5 \\
Catechin gallate & 8.67 & $443>123$ & 5 \\
Theaflavin & 22.09 & $565>139$ & 20 \\
Theaflavin-3-gallate & 20.99 & $717>139$ & 10 \\
Theaflavin-3'-gallate & 23.39 & $717>139$ & 10 \\
Theaflavin-3,3'-digallate & 23.99 & $869>139$ & 2 \\
\hline
\end{tabular}

$0.22 \mu \mathrm{m}$ membrane filter and further diluted using initial mobile phase for the positive ion detection mode. These experiments were performed in three replicates.

\subsection{HPLC-MS-MS analysis}

Ultra high performance liquid chromatography coupled with triple-quadrupole tandem mass spectrometry (HPLC-MS-MS) analysis was performed on Bruker Advance UPLC system coupled with a Bruker EVOQ Elite triple quadrupole mass spectrometer (Bruker, Fremont, CA) which were connected by an electrospray ionization (ESI) source. Samples were injected onto an CAPCELL PAK C18 MGIII $(2.0 \mathrm{~mm} \times 100 \mathrm{~mm}, 3 \mu \mathrm{m})$ column (Shiseido). The flow-rate was $0.3 \mathrm{~mL} \mathrm{~min}^{-1}$, and the column temperature was set at $30^{\circ} \mathrm{C}$. The sensitivity obtained for negative ion mode was much lower than that obtained for positive ion mode, which is in agreement with previously published studies [26]. Thus, positive ion mode was selected as the ionization mode for further optimization experiments.

The mass spectrometer was operated in the positive ESI mode. The multiple reaction monitoring (MRM) mode was use to record the signals. MS-MS analysis was used for the quantification of the compounds with specific calibration curve. Each sample was at least analyzed for three times with an injection volume of $2 \mu \mathrm{L}$.

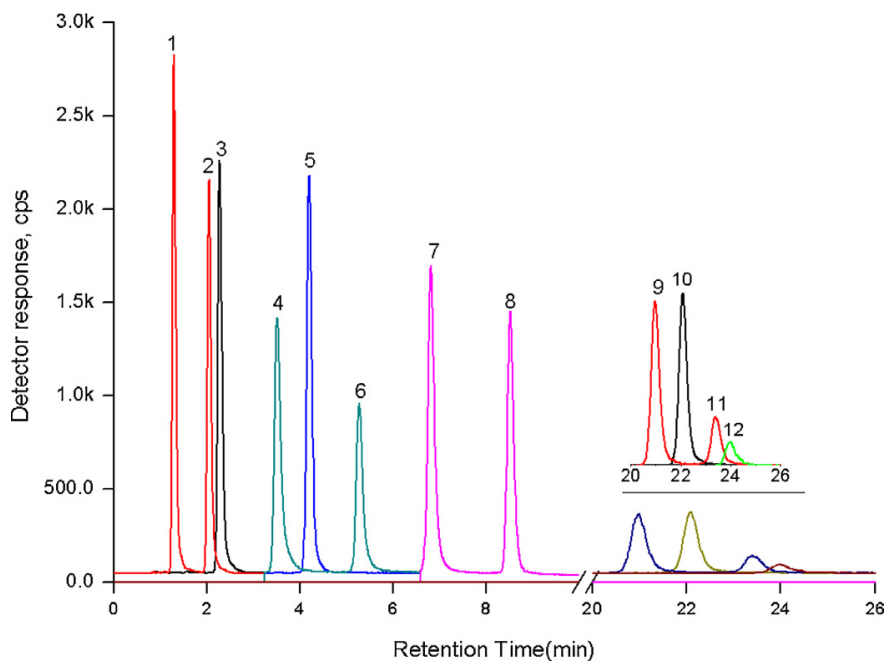

Fig. 2. Chromatogram of a standard mixture of eight tea catechins and four major theaflavins.

1: gallocatechin; 2: epigallocatechin 3: catechin; 4: epigallocatechin gallate; 5: epicatechin; 6: gallocatechin gallate; 7: epicatechin gallate; 8: catechin gallate; 9: theaflavin; 10: theaflavin-3-gallate; 11: theaflavin-3'-gallate; 12: theaflavin-3,3'digallate.
Table 2

Calibration curve range, correlation coefficient and matrix effect for the tested Compounds.

\begin{tabular}{llll}
\hline Compound & $\begin{array}{l}\text { Calibration curve } \\
\text { range }\left(\mu \mathrm{mL}^{-1}\right)\end{array}$ & $\begin{array}{l}\text { Correlation } \\
\text { coefficient }\left(\mathrm{r}^{2}\right)\end{array}$ & $\begin{array}{l}\text { Matrix } \\
\text { effect }\end{array}$ \\
\hline Gallocatechin & $0.02-20$ & 0.9994 & 0.99 \\
Epigallocatechin & $0.02-20$ & 0.9996 & 0.97 \\
Catechin & $0.02-20$ & 0.9974 & 0.96 \\
Epigallocatechin gallate & $0.02-20$ & 0.9998 & 0.94 \\
Epicatechin & $0.02-20$ & 0.9970 & 1.01 \\
Gallocatechin gallate & $0.02-20$ & 0.9996 & 0.98 \\
Epicatechin gallate & $0.02-20$ & 0.9991 & 0.96 \\
Catechin gallate & $0.02-20$ & 0.9996 & 1.12 \\
Theaflavin & $0.02-20$ & 0.9948 & 1.04 \\
Theaflavin-3-gallate & $0.625-20$ & 0.9941 & 0.89 \\
Theaflavin-3'-gallate & $0.625-20$ & 0.9996 & 0.87 \\
Theaflavin-3,3'-digallate & $0.625-20$ & 0.9935 & 1.13 \\
\hline
\end{tabular}

\section{Results and discussion}

\subsection{Optimization for HPLC-MS-MS}

MRM in positive mode with ESI was adopted to obtain better specificity and sensitivity. The nebulizer gas flow and probe gas flow were both set at $60 \mathrm{~mL} \mathrm{~min}^{-1}$. The cone temperature was set at $200^{\circ} \mathrm{C}$ and cone gas flow was set at $20 \mathrm{~mL} \mathrm{~min}^{-1}$. The heated probe temperature was set at $300^{\circ} \mathrm{C}$. Collision energies (modifying its value from 1 to $45 \mathrm{eV}$ ) were optimized for each analytes were listed in Table 1 . These parameters were optimized to acquire higher intensity. The experiments were carried out monitoring the most intense transitions (Table 1).

\subsection{Optimization of HPLC separation of twelve compounds}

The initial HPLC conditions for the separation of catechins were based on the gradient method published in previous reports $[29,30]$. The presence of small concentration of formic acid was necessary for improving the selectivity of the system. The presence of the acid in the mobile phase was also useful for improving the ionization efficiency for MS characterization [31]. Maximal response was achieved with $0.1 \%$ formic acid in the aqueous portion of the mobile phase. Chromatographic separations were performed on a CAPCELL PAK C18 MGIII $(2.0 \mathrm{~mm} \times 100 \mathrm{~mm}, 3 \mu \mathrm{m})$ column (Shiseido). For the separations, the mobile phase consisting of $0.1 \%$ aqueous formic acid (A) and methanol (B) in gradient elution at a flow rate of $0.3 \mathrm{~mL} \mathrm{~min}{ }^{-1}$.

An optimized gradient elution used for HPLC separation was as follows: initial 25\% B; after 2 min percentage of B ramped to $34 \%$ in $7 \mathrm{~min}$, ramped to $42 \%$ at $9.1 \mathrm{~min}$ at once, and ramped to $45 \%$ at $30 \mathrm{~min}$. The equilibration time before next run was $6 \mathrm{~min}$. With

Table 3

Intra-day precision, limits of detection and quantification of the analytes with HPLC-MS-MS.

\begin{tabular}{llll}
\hline Compound & $\begin{array}{l}\text { LOD } \\
\text { (pg/Injection) }\end{array}$ & $\begin{array}{l}\text { LOQ } \\
\text { (pg/Injection) })\end{array}$ & $\begin{array}{l}\text { Intra-day } \\
\text { precision (RSD\%) }\end{array}$ \\
\hline Gallocatechin & 0.16 & 0.54 & 1.12 \\
Epigallocatechin & 0.13 & 0.44 & 2.21 \\
Catechin & 0.19 & 0.64 & 1.39 \\
Epigallocatechin gallate & 0.12 & 0.40 & 3.26 \\
Epicatechin & 0.18 & 0.60 & 2.54 \\
Gallocatechin gallate & 0.12 & 0.40 & 2.19 \\
Epicatechin gallate & 0.20 & 0.67 & 2.73 \\
Catechin gallate & 0.14 & 0.47 & 1.45 \\
Theaflavin & 7.80 & 26.20 & 1.09 \\
Theaflavin-3-gallate & 31.70 & 105.70 & 3.84 \\
Theaflavin-3'-gallate & 99.00 & 330.00 & 5.33 \\
Theaflavin-3,3'-digallate & 223.70 & 745.60 & 3.75 \\
\hline
\end{tabular}




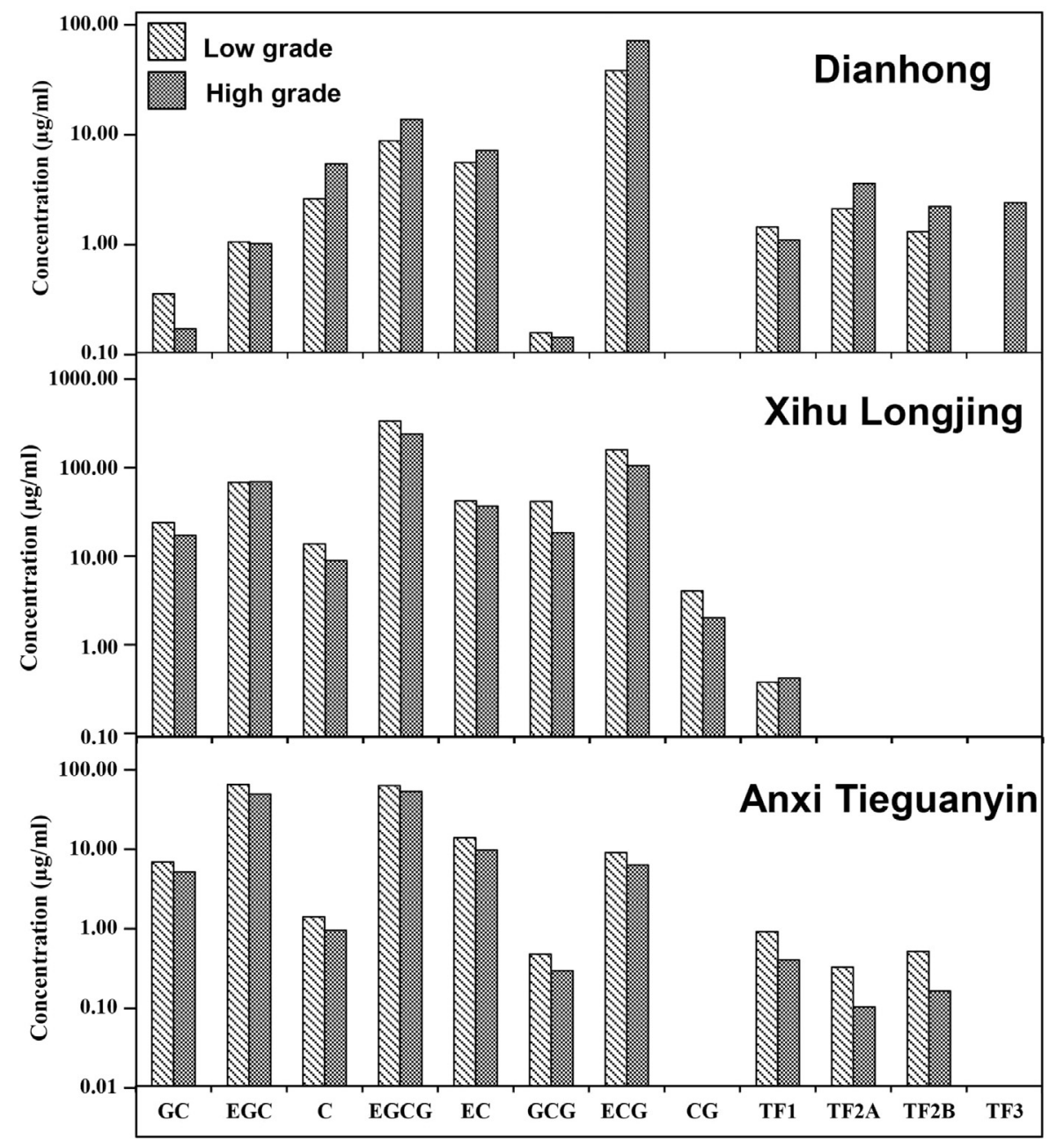

Fig. 3. Concentrations of eight tea catechins and four major theaflavins in three types of tea infusions.

this chromatographic program, all compounds were separated in a total run time of $36 \mathrm{~min}$. The actual separation times for these compounds were less than $30 \mathrm{~min}$. Although isocratic elution could separate all catechins, it was not easy to separate $\mathrm{TF}_{2} \mathrm{~A}$ and $\mathrm{TF}_{2} \mathrm{~B}$ under the described conditions. Fig. 2 depicted a chromatogram of a standard mixture of eight catechins and four theaflavins. Catechins and theaflavins were eluted in the order of GC, EGC, C, EGCG, EC, GCG, ECG, CG, $\mathrm{TF}_{1}, \mathrm{TF}_{2} \mathrm{~A}, \mathrm{TF}_{2} \mathrm{~B}, \mathrm{TF}_{3}$.

\subsection{Analytical parameters of the developed method}

In order to estimate the analytical parameters of the methodology for tea samples, intra-day precision, limits of detection and quantification, matrix effects, and recovery were evaluated. Tables 2 and 3 show results concerning the analytical parameters, such as linearity, precision of the limits of detection and quantification obtained for catechins and theaflavins analysis by HPLC-MS-MS in the three types of tea samples. Five consecutive injections of a mixture of tea extracts were performed during the same day (intra-day precision) to evaluate the method's precision. The results were expressed as relative standard deviations (RSD). RSD values ranged from 1.09 to $5.3 \%$ in intra-day tests and were always lower than $10 \%$, indicating good intra-study variation. Calibration curves were determined for all selected compounds present in tea infusions (Table 2) to assess linearity. Good correlations for all compounds were obtained over the linear dynamic range $\left(0.02-20 \mu \mathrm{g} \mathrm{mL}^{-1}\right)$, and the correlation coefficients $\left(\mathrm{r}^{2}\right)$ were between 0.9935 and 0.9998 . The matrix effect was evaluated comparing the slopes of calibration curves obtained from tea samples spiked at different concentrations with the slope of calibration curve obtained from the results gained for standards. The quotient of the spiked sample curve slope and the standard curve slope higher than 1 indicates existence of ion enhancement. The values lower than 1 show ion suppression. Recovery tests were carried out by spiking the three tea samples at two levels in the range of calibration curve ( 5 and $20 \mu \mathrm{g} \mathrm{mL}^{-1}$, final concentration added) for each compound, three replicates and a procedural blank were also carried out. Recoveries ranged from 65 to $114 \%, 76$ to $93 \%$ and 82 to $115 \%$ with the RSD ranging from $2.4 \%$ to $3.4 \%, 2.9 \%$ to $5.7 \%$ and $3.4 \%$ to $6.7 \%$ for green, black and oolong tea samples, respectively. The variances in the recovery of spiked samples within $\pm 15 \%$ limit were acceptable considering that plant material was analysed. The MRM mode was employed with a HPLC-MS-MS, which had the primary advantage of obtaining high sensitivity for multi-analyte quantitative tests. The detection limits (LODs) and quantification limits (LOQs) were estimated at a signal-to-noise (S/N) ratio of 3 and 10 , respectively, obtaining values in the range from 0.12 to $223.70 \mathrm{pg} /$ injection and 0.40 to $745.60 \mathrm{pg} /$ injection. In general, the HPLC-MS-MS analysis proved to be a very efficient tool for the selected compounds extraction and quantification, revealing excellent performance in terms of linearity, sensitivity, precision and recoveries. 

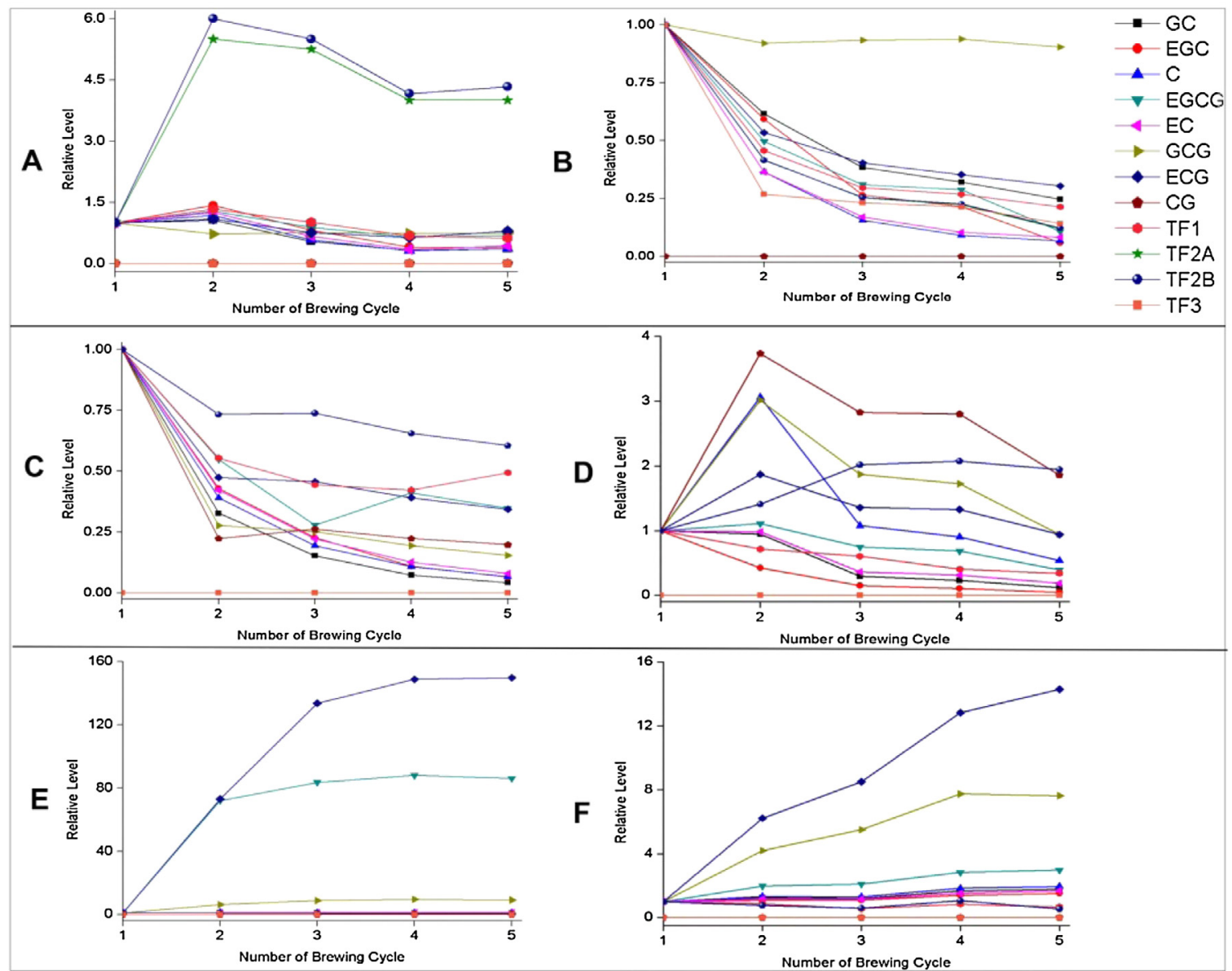

Fig. 4. Relative level of each compound measured after each brewing cycle ${ }^{\mathrm{a}}$.

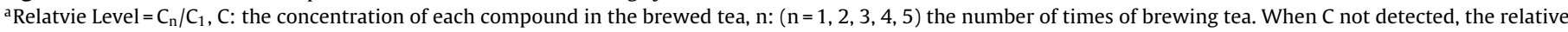
level was equal to zero. A and B were low and high grade Dianhong; C and D were low and high grade Xihu longjing; E and F were low and high grade Anxi tieguanyin.

\subsection{Analysis of tea samples}

Using the developed HPLC-MS-MS method, we determined 12 polyphenol compounds in three kinds of commercial tea samples (green, black and oolong tea samples obtained at a local market), and both samples of high and low grade for each tea were analyzed. Whereas Longjing is one of the most popular green teas consumed in China, Tieguanyin is one of the most popular Chinese oolong teas. Determination results for the eight primary catechins and four major theaflavins in black tea, green tea and oolong tea infusions are provided in Fig. 3 and Table S1 (Supplementary data). As seen in Table S1 and Fig. 3, concentrations of these 12 phenolic compounds are variable according to the type of tea. EGCG, EGC, ECG, EC, GC, C and GCG were identified as major components in all green, black, and oolong tea infusions, which is in agreement with previous studies [32]. The results are also in good agreement with the fact that green tea and oolong tea generally have higher concentrations of catechins such as EC, ECG, EGC and EGCG and only a minute amount of theaflavins. The total concentrations of catechins were 55.3, 690.4 and $157.3 \mu \mathrm{g} \mathrm{mL}^{-1}$ in black, green and oolong teas for low grades. For high grades, the total concentrations were 96.6, 500.1 and $122.6 \mu \mathrm{g} \mathrm{mL}^{-1}$. Regardless of the grade level high or low, the concentrations of total catechins were in the order of: green tea > oolong tea > black tea (Table S1), which is in agreement with the degree of fermentation during manufacturing process [33]. These results were also similar to those observed in commercial teas [32]. The most abundant catechins that were determined in three types of teas were EGCG, ECG and EGC, which constitute over
$80 \%$ of the total amount of all eight primary catechins. The concentration of EGCG in green tea was higher than in other tea samples. In addition, the level of EGCG was higher than other catechins in green and oolong teas, but not black tea. In addition, the total concentration of catechins in low grade green and oolong tea was higher than in high grade green and oolong teas. This result is in agreement with those previously reported [34]. The finding indicated the concentration of catechins is not correlated with price. In contrast, the level of catechins in low grade black tea was lower than in high grade teas. Black tea contains large amounts of theaflavins, which are condensation and polymerization products of catechins during the fermentation process. The total concentration of theaflavins were $3.44,0.41$ and $1.70 \mu \mathrm{g} \mathrm{mL}^{-1}$ in black, green and oolong teas for low grade, respectively; and in high grade, the total concentration were $6.87,0.45$ and $0.65 \mu \mathrm{g} \mathrm{mL}^{-1}$. Trace amounts of theaflavin were also observed in both high and low grade green teas. Both in high and low grade, the level of total theaflavins in black tea were higher than in other tea samples (Fig. 3 and Table S 1). In contrast to oolong teas, the level of theaflavins in low grade black tea was lower than in high grade teas.

The results of measurements taken for each tea sample, brewing in 3 min' length for a total of $15 \mathrm{~min}$, are presented in Fig. 4. As illustrated in Figures A, B, C and D (Fig. 4), concentrations of each compound gradually decreased after each brewing cycle. However, in Figures E and F (Fig. 4), the reverse is observed: concentrations of each compound increased after each brewing cycle. This observation can be explained by the type of teas sampled. Whereas green and black teas are easier to soak through during brewing, oolong 
teas have a 'wrap-curled' texture, therefore requires longer time to be fully brewed. In all three types of tea, the catechins and theaflavins that result from the manufacturing process are important factors in determining the twelve phenolic compounds and overall quality. The present data obtained in the study allowed us to characterize the abundance of selected phenolic compounds in the three types of tea, and the results suggested that people could benefit from regular tea consumption.

\section{Conclusion}

A simultaneous and rapid analytical methodology that could determine eight catechins and four theaflavins in tea samples has been optimized using HPLC-MS-MS. Instrumental parameters such as linearity, reproducibility, repeatability and sensitivity were calculated. Recoveries ranged from 65 to $115 \%$, with acceptable relative standard deviations. The detection limit of the procedure was in the range from 0.12 to $223.70 \mathrm{pg} /$ injection, and validity of the determinations of eight catechins and four theaflavins was verified. The analytical method developed in this study meets all these requirements without requiring an additional clean-up step was needed. In addition, this method could also reduce cost and time invested, in comparison with conventional methods. The optimized methodology has been evaluated with the three types of popular and commercially available tea produced from China. The results indicated that this new method was simultaneous and timeefficient for analyzing these polyphenol compounds in tea samples. Moreover, this method can be used to determine catechins and theaflavins in foods for quality control, beyond its convenient application in evaluation the beneficial health effects of various teas.

\section{Conflict of interest}

On behalf of all authors, the corresponding author states that there is no conflict of interest.

\section{Acknowledgements}

This study was supported by the National Natural Science Foundation of China No. 21525730, the Strategic Priority Research Program of the Chinese Academy of Sciences Nos. XDB14030401 and XDB14030402, National Key Fundamental Research Project (973) (Grant No. 2015CB453101).

\section{Appendix A. Supplementary data}

Supplementary data associated with this article can be found, in the online version, at http://dx.doi.org/10.1016/j.jpba.2016.08.020.

\section{References}

[1] J.M. Hodgson, K.D. Croft, Tea flavonoids and cardiovascular health, Mol. Aspects Med. 31 (2010) 495-502.

[2] D. Grassi, A. Aggio, L. Onori, G. Croce, S. Tiberti, C. Ferri, L. Ferri, G. Desideri, Tea flavonoids, and nitric oxide-mediated vascular reactivity, J. Nutr. 138 (2008) 1554S-1560S

[3] L.M. Yung, F.P. Leung, W.T. Wong, X.Y. Tian, L.H. Yung, Z.Y. Chen, X.Q. Yao, Y. Huang, Tea polyphenols benefit vascular function, Inflammopharmacology 16 (2008) 230-234.

[4] S. Liu, F. Liu, Y. Xue, Y. Gao, Evaluation on oxidative stability of walnut beverage emulsions, Food Chem. 203 (2016) 409-416.

[5] S. Sur, D. Pal, R. Roy, A. Barua, A. Roy, P. Saha, C.K. Panda, Tea polyphenols EGCG and TF restrict tongue and liver carcinogenesis simultaneously induced by $N$-nitrosodiethylamine in mice, Toxicol. Appl. Pharmacol. 300 (2016) 34-46.

[6] P. Wang, S.M. Henning, C.E. Magyar, Y. Elshimali, D. Heber, J.V. Vadgama, Green tea and quercetin sensitize PC-3 xenograft prostate tumors to docetaxel chemotherapy, J. Exp. Clin. Cancer Res. 35 (2016) 73-83.
[7] Z. Liu, Z. Luo, C. Jia, D. Wang, D. Li, Synergistic effects of Potentilla fruticosa L, leaves combined with green tea polyphenols in a variety of oxidation systems, J. Food Sci. 81 (2016) C 1091-C 1101.

[8] H.W. Liu, C.C. Wei, S.J. Chang, Low-molecular-weight polyphenols protect kidney damage through suppressing NF- $\mathrm{KB}$ and modulating mitochondrial biogenesis in diabetic db/db mice, Food Funct. 7 (2016) 1941-1949.

[9] M. Weerawatanakorn, W.L. Hung, M.H. Pan, S. Li, D. Li, X.H. Wang, C.T. Ho, Chemistry and health beneficial effects of oolong tea and theasinensins, Food Sci. Hum. Wellness 4 (2015) 133-146.

[10] S. Li, M.H. Pan, C.Y. Lo, C.S. Lai, C.T. Ho, Black tea: chemical analysis and stability, Food Funct. 4 (2013) 10-18.

[11] D.W. Li, M. Zhu, Y.D. Shao, Z. Shen, C.C. Weng, W.D. Yan, Determination and quality evaluation of green tea extracts through qualitative and quantitative analysis of multi-components by single marker (QAMS), Food Chem. 197 (2016) 1112-1120

[12] A. Finger, S. Kuhr, U.H. Engelhardt, Chromatography of tea constituents, J. Chromatogr. 624 (1992) 293-315.

[13] W.E. Bronner, G.R. Beecher, Method for determining the content of catechins in tea infusions by high-performance liquid chromatography, J. Chromatogr. A. 805 (1998) 137-142.

[14] Q. Liu, W.S. Cai, X.G. Shao, Determination of seven polyphenols in water by high performance liquid chromatography combined with preconcentration, Talanta 77 (2008) 679-683.

[15] T. Goto, Y. Yoshida, M. Kiso, H. Nagashima, Simultaneous determination of individual catechins and caffeine in green tea, J. Chromatogr. A. 749 (1996) 295-299

[16] J.K. Lin, C.L. Lin, Y.C. Liang, S.Y. Lin-Shoei, I.M. Jn, Survey of catechins gallic acid and methylxanthines in green oolong, pu-erh, and black teas, J. Agric. Food Chem. 46 (1998) 3635-3642.

[17] M.J. Lee, S. Prabhu, X. Meng, C. Li, C.S. Yang, An improved method for the determination of green tea polyphenols in biomatrixes by high-performance liquid chromatography with coulometric array detection, Anal. Biochem. 279 (2000) 164-169

[18] C. Cabrera, R. Giménez, M.C. López, Determination of tea components with antioxidant activity, J. Agric. Food Chem. 51 (2003) 4427-4435.

[19] R.G. Bailey, H.E. Nursten, I. Mcdowell, A comparison of the hplc mass spectra, and acid degradation of theafulvins from black tea and proanthocyanidin polymers from wine and cider, J. Sci. Food Agric. 66 (1994) 231-238.

[20] L.Z. Lin, P. Chen, J.M. Harnly, New phenolic components and chromatographic profiles of green and fermented teas, J. Agric. Food Chem. 56 (2008) 8130-8140.

[21] A. Kiehne, U.M. Engelhardt, Thermospray-LC-MS analysis of various groups of polyphenols in tea, Z. Lebensm Unters Forsch. 202 (1996) 299-302.

[22] Y. Sapozhnikova, Development of liquid chromatography-tandem mass spectrometry method for analysis of polyphenolic compounds in liquid samples of grape juice, green tea and coffee, Food Chem. 150 (2014) 87-93.

[23] D. Wang, J. Lu, A. Miao, Z. Xie, D. Yang, HPLC-DAD-ESI-MS/MS analysis of polyphenols and purine alkaloids in leaves of 22 tea cultivars in China, J. Food Compos. Anal. 21 (2008) 361-369.

[24] P. Svoboda, H. Vlčková, L. Nováková, Development and validation of UHPLC-MS/MS method for determination of eight naturally occurring catechin derivatives in various tea samples and the role of matrix effects, J. Pharm. Biomed. Anal. 114 (2015) 62-70.

[25] N. Marina, F. Jessica, G. Roberto, P. Aurélie, V. Jean-Luc, G. Davy, A. Vincenza, Simultaneous detection of green tea catechins and gallic acid in human serum after ingestion of green tea tablets using ion-pair high-performance liquid chromatography with electrochemical detection, J. Pharm. Biomed. Anal. 88 (2014) 307-314.

[26] Z. Spáčil, L. Nováková, P. Solich, Comparison of positive and negative ion detection of tea catechins using tandem mass spectrometry and ultra-high performance liquid chromatography, Food Chem. 123 (2010) 535-541.

[27] C. Fanali, A. Rocco, Z. Aturki, L. Mondello, S. Fanali, Analysis of polyphenols methylxantines in tea samples by means of nano-liquid chromatography utilizing capillary columns packed with core-shell particles, J. Chromatogr A 1234 (2012) 38-44

[28] B.L. Lee, C.N. Ong, Comparative analysis of tea catechins and theaflavins by high-performance liquid chromatography and capillary electrophoresis, J. Chromatogr. A 881 (2000) 439-447.

[29] Z. Spáčil, L. Nováková, P. Solich, Analysis of phenolic compounds by high performance liquid chromatography and ultra performance liquid chromatography, Talanta 76 (2008) 189-199.

[30] D. Del Rio, A.J. Stewart, W. Mullen, J. Burns, M.E. Lean, F. Brighenti, A. Crozier, HPLC-MSn analysis of phenolic compounds and purine alkaloids in green and black tea, J. Agric. Food Chem. 52 (2004) 2807-2815.

[31] C.A. Hughey, B. Wilcox, C.S. Minardi, C.W. Takehara, M. Sundararaman, L.M. Were, Capillary liquid chromatography-mass spectrometry for the rapid identification and quantification of almond flavonoids, J. Chromatogr. A. 1192 (2008) 259-265.

[32] Y. Zuo, H. Chen, Y. Deng, Simultaneous determination of catechins, caffeine and gallic acids in green oolong, black and pu-erh teas using HPLC with a photodiode array detector, Talanta 57 (2002) 307-316.

[33] M.T. Huang, C.T. Ho, C.Y. Lee, Phenolic Compounds in Food and Their Effects on Health II: Antioxidants and Cancer Prevention, American Chemical Society, Washington, DC, 1992

[34] T. Goto, Y. Yoshida, M. Kiso, H. Nagashima, Simultaneous analysis of individual catechins and caffeine in green tea, J. Chromatogr. A 749 (1996) 295-299. 